\title{
ENTHALPY RELAXATION PHENOMENON OF HEAVY IGE*
}

\author{
By Osamu Haida, $\uparrow$ Hiroshi Suga, and Syūzō Seki \\ (Department of Chemistry, Faculty of Science, Osaka University, Toyonaka, Osaka, Japan)
}

\begin{abstract}
The heat capacities of quenched and annealed heavy ice Ih were measured in the temperature range 14 to $300 \mathrm{~K}$ by an adiabatic calorimeter. A relaxational thermal anomaly was found at around I I $5 \mathrm{~K}$ and this phenomenon was ascribed to the onset of deuteron ordering in the crystal. The average activation enthalpy of the relaxational process was determined to be $(26 \pm 5) \mathrm{kJ} \mathrm{mol}^{-1}$. Residual entropies of the crystal were recalculated on the basis of the present heat-capacity data combined with the revised values for enthalpy of vapourization, saturated vapour pressure, and spectroscopic entropy. They are $(3.47 \pm 0.4 \mathrm{I}) \mathrm{J} \mathrm{K}^{-1} \mathrm{~mol}^{-1}$ for the quenched crystal and $(3.44 \pm 0.4 \mathrm{I}) \mathrm{J} \mathrm{K}^{-1} \mathrm{~mol}^{-1}$ for the crystal annealed at $102-106 \mathrm{~K}$ for $264 \mathrm{~h}$. The characteristics and the origin of the anomaly are discussed in comparison with that of ordinary ice.

RÉsumÉ. Phenomène de relaxation enthalpique de la glace "lourde". Les capacités calorifiques de glace Ih lourde trempée et recuite sont mesurées entre 14 et $300 \mathrm{~K}$ grâce à un calorimètre adiabatique. Une anomalie de relaxation thermique a été trouvée autour de I I $5 \mathrm{~K}$ et ce phénomène est attribué à l'apparition d'un ordre des deutériums dans le cristal. L'enthalpie d'activation du processus de relaxation est de $(26 \pm 5)$ $\mathrm{kJ} \mathrm{mol}^{-\mathrm{r}}$. Les entropies résiduelles du cristal ont été recalculées grâce aux présents résultats de capacité calorifique combinés aux nouvelles valeurs de l'enthalpie de vaporisation, de pression, de vapeur saturante et d'entropie spectroscopique. On trouve $(3,47 \pm 0,4 \mathrm{I}) \mathrm{J} \mathrm{K}^{-1} \mathrm{~mol}^{-1}$ pour le cristal trempé et $(3,44 \pm 0,4 \mathrm{I})$ $\mathrm{J} \mathrm{K}^{-1} \mathrm{~mol}^{-1}$ pour le cristal recuit à $102-106 \mathrm{~K}$ pendant $264 \mathrm{~h}$. Les caractéristiques et les origines de l'anomalie sont discutées en comparaison avec celle de la glace ordinaire.

Zusammenfassung. Enthalpierelaxationserscheinung des schweren Eises. Die Wärmekapazitäten von abgeschrecktem und getempertem schweren Eis Ih wurden im Temperaturbereich 14 bis $300 \mathrm{~K}$ mit einem adiabatischen Kalorimeter gemessen. Eine thermische Relaxationsanomalie wurde um i I $5 \mathrm{~K}$ gefunden, und diese Erscheinung wurde dem Einsetzen einer Ausordnung der Deuteronen im Kristall zugschrieben. Die Aktivierungsenthalpie des Relaxationsprozess wurde $\mathrm{zu}(26 \pm 5) \mathrm{kJ} \mathrm{mol}^{-1}$ bestimmt. Die Restentropien des Kristalls wurden neu berechnet auf der Grundlage der gegenwärtigen Wärmekapazitätswerte in Verbindung mit den überprüften Werten für die Verdampfungsenthalpie, Dampfsättigungsdruck und spektroskopische Entropie. Sie betragen $(3,47 \pm 0.4 \mathrm{I}) \mathrm{J} \mathrm{K}^{-1} \mathrm{~mol}^{-1}$ für die abgeschreckten Kristalle und $(3,44 \pm 0,4 \mathrm{I})$ $\mathrm{J} \mathrm{K}^{-1} \mathrm{~mol}^{-1}$ für den bei $102-106 \mathrm{~K}$ für $264 \mathrm{~h}$ getemperten Kristall. Die Merkmale und der Ursprung der Anomalie werden im Vergleich zu gewöhnlichem Eis besprochen.
\end{abstract}

\section{INTRODUCTION}

The structural features of hexagonal ice as revealed by various experimental techniques and theoretical consideration are that, while the oxygen atoms form a regular hexagonal lattice, the hydrogen atoms are arranged randomly in that structure. Since such a disordered structure contradicts the Third Law of Thermodynamics, search for a possible ordering of the proton system at low temperatures has been one of the main subjects of recent investigation of hexagonal ice. Haida and others (1974) reported new facts concerning this subject. In that study, the heat capacities were measured for $\mathrm{H}_{2} \mathrm{O}$ ice quenched and annealed at several temperatures below $100 \mathrm{~K}$ and at around $100 \mathrm{~K}$ the heat-capacity values were found to be clearly dependent upon thermal history of the crystal. The spontaneous temperature rise during the annealing experiment was followed to obtain the characteristic time for enthalpy relaxation. They interpreted these phenomena as follows: As the temperature is lowered, change in the proton configuration becomes suppressed on its way to achieving a more ordered state because of the prolonged relaxation time for realizing the process.

If this is the case, we naturally expect a similar behaviour in $\mathrm{D}_{2} \mathrm{O}$ ice. Already, there have been some attempts to find a similar anomaly in $\mathrm{D}_{2} \mathrm{O}$ ice corresponding to that in $\mathrm{H}_{2} \mathrm{O}$ ice around $100 \mathrm{~K}$. Many years ago, Long and Kemp (1936) measured the heat capacity of $\mathrm{D}_{2} \mathrm{O}$ ice by use of the same calorimeter employed for $\mathrm{H}_{2} \mathrm{O}$ ice and showed the existence of finite

* Paper accepted for the Symposium on the Physics and Chemistry of Ice, Cambridge, 1977, but not presented because of the absence of the authors.

$\dagger$ Present address: Research Laboratory, Kawasaki Steel Co., I Kawasakicho Chiba, Japan. 
residual entropy $\left(3.22 \mathrm{~J} \mathrm{~K}^{-1} \mathrm{~mol}^{-1}\right)$ just as in the case of $\mathrm{H}_{2} \mathrm{O}$ ice. Nevertheless, they were unable to detect any phenomena of slow attainment to thermal equilibrium in spite of their intention inspired by the report of Giauque and Stout (1936). On the other hand, recent investigations of elastic moduli for $\mathrm{D}_{2} \mathrm{O}$ ice by Helmreich (1973) showed anomalous behaviour at temperatures between 100 and $150 \mathrm{~K}$. Thus the present study on $\mathrm{D}_{2} \mathrm{O}$ ice was aimed at

TABle I. Molar heat capacities of DEUTERIUM OXIDE

(Molecular weight $=20.028)$

\begin{tabular}{|c|c|c|}
\hline$T_{\mathrm{av}}$ & $C_{\mathrm{s}}$ & $\underline{\Delta T}$ \\
\hline$\overline{\mathrm{K}}$ & $\overline{\mathrm{J} \mathrm{K}^{-1} \mathrm{~mol}^{-1}}$ & $\overline{\mathrm{K}}$ \\
\hline 13.80 & $\begin{array}{r}\text { Crystal } \\
0.888\end{array}$ & 0.506 \\
\hline 14.47 & 0.959 & 0.511 \\
\hline 15.01 & 1.064 & 0.574 \\
\hline I 5.71 & 1.193 & 0.820 \\
\hline I 6.47 & 1. 364 & 0.857 \\
\hline 17.40 & 1. 559 & $0.86 \mathrm{I}$ \\
\hline 18.29 & I. 764 & 0.890 \\
\hline I9. I9 & 1. $94^{8}$ & 0.960 \\
\hline 20.15 & 2.185 & 0.955 \\
\hline 2 I. I 4 & $2.4 I^{I}$ & $0.9^{89}$ \\
\hline 22.13 & 2.644 & 0.979 \\
\hline 23.17 & 2.883 & 1.086 \\
\hline 24.28 & 3.147 & I. 269 \\
\hline 25.49 & 3.390 & I. 145 \\
\hline 26.79 & 3.690 & I. 33 I \\
\hline 28.12 & 3.975 & 1.328 \\
\hline 29.44 & 4.279 & I. 321 \\
\hline 30.87 & $4 \cdot 55^{8}$ & I. $53^{2}$ \\
\hline $3^{2} \cdot 39$ & 4.866 & 1.510 \\
\hline 33.88 & 5.175 & I. 465 \\
\hline $35 \cdot 4^{8}$ & 5.490 & I. 733 \\
\hline 37.21 & 5.833 & 1.739 \\
\hline 38.93 & 6.156 & เ. 696 \\
\hline 40.63 & $6.48 \mathrm{I}$ & г. 689 \\
\hline 42.35 & 6.814 & I. $76 \mathrm{I}$ \\
\hline 44.12 & 7.106 & 1. 769 \\
\hline 45.94 & 7.446 & 1.885 \\
\hline 47.85 & 7.786 & I. 928 \\
\hline $49 \cdot 79$ & 8.128 & 1.960 \\
\hline $5^{1.74}$ & $8.4^{80}$ & I.935 \\
\hline $53.7^{2}$ & $8.84^{8}$ & 2.029 \\
\hline $55 \cdot 79$ & 9.233 & 2.116 \\
\hline $57 \cdot 9^{2}$ & 9.607 & 2.1 43 \\
\hline 60.10 & $9 \cdot 9^{85}$ & 2.316 \\
\hline 62.30 & 10.37 & 2.1 94 \\
\hline 64.55 & 10.76 & $2.3^{16}$ \\
\hline 66.88 & I1.16 & $2.34^{2}$ \\
\hline 69.21 & I 1.57 & 2.328 \\
\hline 70.21 & I 1.74 & $2.55^{2}$ \\
\hline 72.72 & 12.18 & 2.465 \\
\hline 75.14 & 12.60 & 2.368 \\
\hline $77 \cdot 4^{8}$ & 13.02 & 2.317 \\
\hline 79.84 & I 3.4 I & $2.04^{1}$ \\
\hline 81.86 & 1 3.75 & 2.000 \\
\hline 84.08 & 14.14 & $2.44^{\circ}$ \\
\hline $86.4^{8}$ & 14.55 & 2.36 \\
\hline 88.82 & I 4.95 & $2 \cdot 3^{26}$ \\
\hline \multicolumn{3}{|c|}{ (Series I) } \\
\hline 88.53 & 14.90 & 2.202 \\
\hline 90.70 & 15.29 & 2.13 \\
\hline $92.8 \mathrm{I}$ & I 5.64 & 2.06 \\
\hline 94.90 & I 5.99 & 2.06 \\
\hline $9^{6.95}$ & I 6.35 & 2.04 \\
\hline 99.17 & 16.73 & 2.40 \\
\hline
\end{tabular}

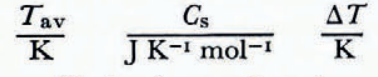

(Series I) - continued

$\begin{array}{lll}\text { 101.55 } & 17.13 & 2.354 \\ 103.69 & 17.51 & 1.922 \\ 105.61 & 17.83 & 1.898 \\ 107.49 & 18.16 & 1.870 \\ 109.54 & 18.51 & 2.207 \\ 111.75 & 18.88 & 2.194 \\ 114.10 & 19.29 & 2.471 \\ 115.54 & 19.74 & 2.427 \\ 118.95 & 20.17 & 2.384 \\ 121.32 & 20.59 & 2.346 \\ 123.71 & 21.02 & 2.426 \\ 126.11 & 21.46 & 2.383 \\ 128.48 & 21.86 & 2.349 \\ 130.81 & 22.27 & 2.319 \\ 133.12 & 22.68 & 2.283 \\ 135.38 & 23.07 & 2.253 \\ & & \end{array}$

(Series 2)

$\begin{array}{lll}103.67 & 17.48 & 2.789 \\ 106.47 & 17.97 & 2.426 \\ 108.68 & 18.45 & 2.385 \\ 111.04 & 18.91 & 2.335 \\ 113.34 & 19.34 & 2.274 \\ 115.61 & 19.75 & 2.251 \\ 117.89 & 20.16 & 2.314 \\ 120.20 & 20.56 & 2.298 \\ 122.48 & 20.94 & 2.261 \\ 124.72 & 21.29 & 2.228 \\ 126.92 & 21.67 & 2.174 \\ 129.15 & 22.04 & 2.289 \\ 131.43 & 22.40 & 2.275 \\ 133.68 & 22.79 & 2.236\end{array}$

(Series 3)

I I 1.18

I 3.19

I 15.09

116.97
118.86

120.77

122.71

124.68

126.62

128.54

130.49

I 32.46

1 34.4 I

136.65
I 39.07

141.45

143.80

144.49

146.73

I 49.2 I

$\begin{array}{ll}18.86 & 2.120 \\ 19.25 & 1.912 \\ 19.5^{8} & 1.889 \\ 19.92 & 1.863 \\ 20.29 & 1.926 \\ 20.63 & 1.900 \\ 20.95 & 1.977 \\ 21.26 & 1.955 \\ 21.59 & 1.929 \\ 21.90 & 1.910 \\ 22.23 & 1.987 \\ 22.58 & 1.962 \\ 22.90 & 1.938 \\ 23.29 & 2.429 \\ 23.69 & 2.402 \\ 24.09 & 2.367 \\ 24.49 & 2.336 \\ 24.60 & 2.046 \\ 24.99 & 2.422 \\ 25.37 & 2.538\end{array}$

$\frac{T_{\mathrm{av}}}{\mathrm{K}} \quad \frac{C_{\mathrm{s}}}{\mathrm{J} \mathrm{K}^{-1} \mathrm{~mol}^{-1}} \quad \frac{\Delta T}{\mathrm{~K}}$

(Series 3)-continued

\begin{tabular}{|c|c|c|}
\hline 151.73 & 25.80 & \\
\hline 154.21 & 26.22 & 2.469 \\
\hline 156.67 & 26.62 & $2.43^{8}$ \\
\hline I 59.09 & 27.01 & $2.41 \mathrm{II}$ \\
\hline 161.49 & 27.43 & $2.3^{81}$ \\
\hline 163.51 & 27.75 & 3.001 \\
\hline $166.4^{8}$ & 28.24 & $2.9^{21}$ \\
\hline I69.38 & 28.71 & 2.890 \\
\hline 1 72.36 & 29.18 & 3.070 \\
\hline 175.42 & 29.70 & $2.04^{2}$ \\
\hline 176.33 & 29.85 & 3.050 \\
\hline I $79 \cdot 36$ & 30.32 & 3.005 \\
\hline 182.33 & $30.8 \mathrm{I}$ & $2.94^{6}$ \\
\hline 185.25 & 31.30 & $2.89 \mathrm{I}$ \\
\hline 188.32 & 31.78 & $3.25^{8}$ \\
\hline 191.86 & $3^{2.36}$ & 3.232 \\
\hline 195.07 & 32.84 & 3.189 \\
\hline 198.24 & 33.37 & 3.157 \\
\hline $201 \cdot 38$ & 33.88 & 3.115 \\
\hline 204.46 & $34 \cdot 37$ & 3.057 \\
\hline $207.5^{\circ}$ & 34.83 & 3.030 \\
\hline $210.5^{2}$ & $35 \cdot 32$ & 2.997 \\
\hline $2 \times 3.60$ & 35.81 & 3.1 59 \\
\hline 216.74 & 36.29 & $3.13^{6}$ \\
\hline 219.85 & 36.78 & 3.077 \\
\hline 222.92 & 37.30 & 3.055 \\
\hline 225.95 & 37.72 & 3.022 \\
\hline 228.96 & 38.22 & 2.985 \\
\hline 232.04 & $3^{8.68}$ & 3.189 \\
\hline 235.22 & 39.21 & 3.160 \\
\hline $23^{8} \cdot 3^{6}$ & 39.69 & 3.125 \\
\hline 241.47 & 40.16 & 3.085 \\
\hline 244.54 & 40.66 & 3.054 \\
\hline $247 \cdot 56$ & 41.12 & $2.99^{6}$ \\
\hline 250.58 & $4^{1} \cdot 5^{6}$ & 3.030 \\
\hline $253.5^{8}$ & $4^{2.06}$ & 2.967 \\
\hline 256.65 & $4^{2.55}$ & $3.18 \mathrm{I}$ \\
\hline 259.82 & 43.04 & $3.16 \mathrm{I}$ \\
\hline 262.96 & 43.57 & 3.113 \\
\hline 266.07 & 44.06 & 3.100 \\
\hline 269.27 & 44.61 & $3 \cdot 315$ \\
\hline $272.4^{2}$ & $\begin{array}{l}45 \cdot 31 \\
47.18\end{array}$ & 2.984 \\
\hline 275.12 & 47.18 & 2.402 \\
\hline & . Liquid & \\
\hline $280.5 \mathrm{I}$ & 86. I 5 & 1. 936 \\
\hline 282.45 & 85.95 & I.95I \\
\hline 284.49 & 85.71 & 2.128 \\
\hline 286.61 & 85.55 & 2.107 \\
\hline 288.73 & & 2.1 34 \\
\hline 291.03 & & $2.47 \mathrm{I}$ \\
\hline 3.52 & 85.06 & 2.492 \\
\hline 296.01 & $84.9 \mathrm{I}$ & 2.495 \\
\hline 298.50 & 84.78 & 2.495 \\
\hline & & 1.786 \\
\hline
\end{tabular}


finding the expected anomaly analogous to that in $\mathrm{H}_{2} \mathrm{O}$ ice and also to detect some isotope effects on the relaxational ordering process if any. A brief description of the experimental results was reported by Haida and others (1973).

\section{EXPERIMENTAL}

The heat capacities of $\mathrm{D}_{2} \mathrm{O}$ ice were measured by the same calorimeter and auxiliary apparatus used in the investigation of $\mathrm{H}_{2} \mathrm{O}$ ice. Briefly, it is an adiabatic calorimeter with an intermittent heating method. The performance of the adiabatic control is such that natural heat leakage to the calorimeter cell including self-heating due to thermometer current is about $8 \mu \mathrm{J} \mathrm{s}^{-1}$ at around roo $\mathrm{K}$. The precision of the measurements was, in general, better than $0.1 \%$.

Heavy water obtained from E. Merck (99.75\% deuteration level) was degassed carefully by freeze-pump-thaw cycles in vacuo. The sample was then distilled and the middle fraction $\left(3^{2} .3^{8} \mathrm{I} \mathrm{g}\right)$ was introduced into the calorimeter cell by vacuum distillation. The $\mathrm{D}_{2} \mathrm{O}$ ice crystal made in the calorimeter cell in situ was annealed at $273.6 \mathrm{~K}$ for about $3 \mathrm{~d}$ and then cooled down to $77 \mathrm{~K}$ at a rate of about $-1 \mathrm{~K} \mathrm{~min}-1$ ("quenched" sample).

\section{EXPERIMENTAL RESULTS}

\section{Heat-capacity measurement}

The heat capacities of $\mathrm{D}_{2} \mathrm{O}$ ice were measured in the temperature range between $\mathrm{I}_{4}$ and $300 \mathrm{~K}$ along the same lines as the study on $\mathrm{H}_{2} \mathrm{O}$ ice. The first series of measurement is for a "quenched" sample, while the data for Series 2 and 3 correspond to the ones annealed at I02-106 K for $264 \mathrm{~h}$ and at $\mathrm{I}$ Iо $\mathrm{K}$ for $\mathrm{I} 66 \mathrm{~h}$, respectively. The heat-capacity data are listed in Table I. For all of these series of measurements, there appeared a lag in equilibrium in the temperature region around I $_{5} \mathrm{~K}$. This observation stands in contrast to Long and Kemp's result. These thermal anomalies are illustrated in Figure I. "Temperature drift", the ordinate of the figure, is the value $\{T$ (30 $\mathrm{min})-T($ I $0 \mathrm{~min})\}$, where $T(t)$ is the temperature at time $t$; the time origin is the end-point of energy input. For Series $\mathrm{I}$, an exothermic temperature drift was observed, while an endothermic one was observed for Series 2 and 3 in the temperature range between 100 and $130 \mathrm{~K}$. The reversal of the temperature drift from exothermic to endothermic by annealing and also the increase of temperature drift by annealing at lower temperature for longer periods found in these measurements are characteristic of relaxation phenomena which appear in a glass-transition region of the frozen-in disordered system. Thus, some degrees of freedom in $\mathrm{D}_{2} \mathrm{O}$ ice crystals must be frozen around I $5 \mathrm{~K}$.

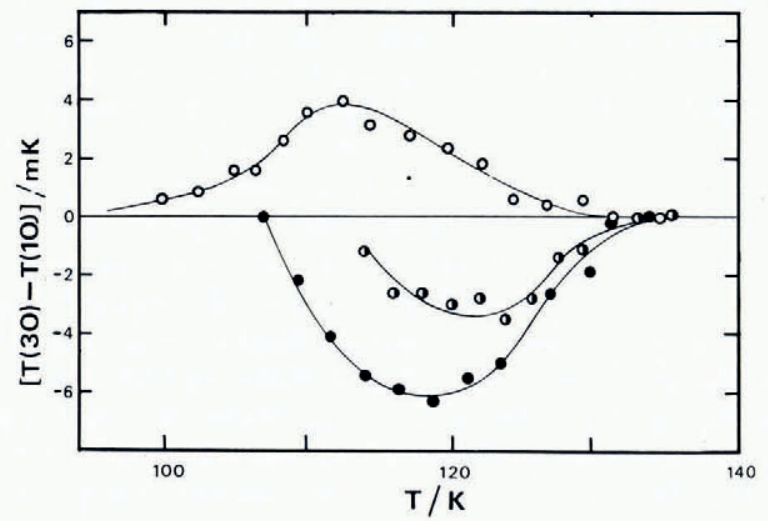

Fig. I. Anomalous temperature drift observed in $\mathrm{D}_{2} \mathrm{O}$ ice. $\bigcirc$ Series $\mathrm{I}$, Series 2, O Series 3 . 
The heat-capacity data for the quenched and the annealed samples are shown in Figure 2 in the form of $\left(C_{p} / T\right)$ versus $T$. The data for annealed samples (Series 2 and 3 ) exceed those for the quenched one (Series I), the excess part being dependent on the annealing temperature.

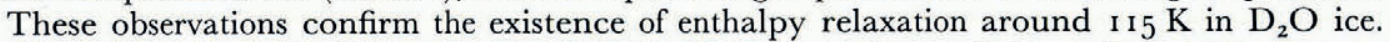
Since deuterons in $\mathrm{D}_{2} \mathrm{O}$ ice have the disordered configuration, and since all the high-pressure polymorphs of ice reach some degree of order at low temperature, it seems natural to ascribe these anomalies to the relaxational deuteron ordering as described below.

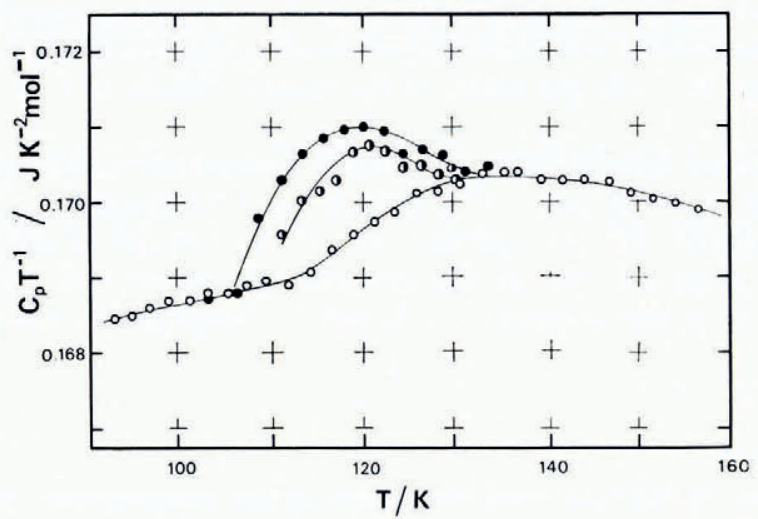

Fig. 2. $C_{p} / T$ of $D_{2} O$ ice plotted against temperature. $\bigcirc$ Series $I$,

Series 2, Series 3 .

\section{Enthalpy of fusion}

The equilibrium temperatures of the fractional melting were measured and from the results, the triple point and liquid (soluble), solid (insoluble) impurities were determined to be $276.95 \mathrm{~K}$ and $0.0005 \%$, respectively. The specimen used is claimed by the manufacturer to contain $0.25 \%$ isotopic impurity. Therefore the isotopic impurity would not affect the melting behaviour. This fact was already noticed by Long and Kemp, and also observed for $\mathrm{H}_{2} \mathrm{O}$ ice by us.

The molar enthalpy of fusion, $6314.6 \mathrm{~J} \mathrm{~mol}^{-1}$, is in reasonable agreement with that of Long and Kemp (1936) and those cited in their paper.

\section{Residual entropy}

The residual entropy calculated by Long and $\mathrm{Kemp}$ for $\mathrm{D}_{2} \mathrm{O}$ ice had a discrepancy with that for $\mathrm{H}_{2} \mathrm{O}$ ice. If the sophisticated theoretical work by Nagle (1966) describes well the actual status of the disordered proton system, this value corresponds to $6 \%$ of deuteron ordering. This seems to be too much in view of the fact that merely $2 \%$ of the residual entropy of $\mathrm{H}_{2} \mathrm{O}$ ice was removed by annealing the crystal over a period longer than $30 \mathrm{~d}$ as revealed by Haida and others (1974). It seems worthwhile, therefore, to retest the value using recent more reliable data since the attainment of a more ordered state is eagerly desired for the conclusive interpretation of the anomaly at around $100 \mathrm{~K}$ in $\mathrm{H}_{2} \mathrm{O}$ ice.

The calculation of the residual entropy was carried out by using our data along with the following values. The values of the molar enthalpy of vapourization, saturated vapour pressure, and the spectroscopic entropy of standard ideal gaseous state at $25^{\circ} \mathrm{C}$ were obtained from the works by Rossini and others (1940) and by Besley and Bottomley (1973). The residual entropies were found to be 3.47 (Series I), 3.44 (Series 2), and 3.45 (Series 3) $\pm 0.4 \mathrm{I}$ $\mathrm{J} \mathrm{K}^{-1} \mathrm{~mol}^{-1}$, respectively, as shown in Table II. These values are comparable in magnitude with those for $\mathrm{H}_{2} \mathrm{O}$ ice. The isotope effect on the residual entropy is much less than that considered hitherto. 
TAble II. Residual entropy of hexagonal heavy ice

\begin{tabular}{|c|c|c|}
\hline $\begin{array}{c}\text { Temperature } \\
\text { range } \\
T \\
\mathrm{~K}\end{array}$ & Source & $\begin{array}{l}\text { Entropy } \\
\text { change } \\
\Delta S \\
\mathrm{~J} \mathrm{~K}^{-1} \mathrm{~mol}^{-1}\end{array}$ \\
\hline $0-13$ & Debye extrapolation & 0.232 \\
\hline $13-276.95$ & $\begin{array}{r}\int\left(C_{\mathrm{s}} / T\right) \mathrm{d} T \text { (graphical) } \\
(\text { for quenched sample) }\end{array}$ & $43 \cdot 345 \pm 0.08$ \\
\hline 276.95 & Melting $6314.6 / 276.95$ & $22.78_{1} \pm 0.04$ \\
\hline $276.95^{-298.15}$ & $\int\left(C_{\mathrm{s}} / T\right) \mathrm{d} T$ (graphical) & $6.3 \mathrm{O}_{4} \pm 0.0 \mathrm{I}$ \\
\hline \multirow[t]{4}{*}{298.15} & $\begin{array}{l}\text { Vapourization } 45 \cdot 398 / 298.15 \\
\text { Compression } R \ln (20.510 / 760) \\
\text { Gas imperfection }\end{array}$ & $\begin{array}{l}152.266 \pm 0.15 \\
-30.030 \pm 0.03 \\
0.009\end{array}$ \\
\hline & Total & $194.92_{7} \pm 0.31$ \\
\hline & $\begin{array}{l}\text { Spectroscopic entropy } \\
\quad\left(\text { ideal gas at } 101.325 \mathrm{kPa}, 25^{\circ} \mathrm{C} \text { ) }\right.\end{array}$ & I $98.4 \pm 0 . \mathrm{I}$ \\
\hline & $\begin{array}{l}\text { Residual entropy: } \\
\text { quenched sample } \\
\text { annealed sample (series 2) } \\
\text { annealed sample (series 3) }\end{array}$ & $\begin{array}{l}3.47 \pm 0.4^{1} \\
3.44 \pm 0.4^{1} \\
3.45 \pm 0.4^{1}\end{array}$ \\
\hline
\end{tabular}

The theoretical value of the residual entropy for a hypothetical completely disordered crystal based on the Bernal-Fowler-Pauling statistical model is $(3.408 \pm 0.0008) \mathrm{J} \mathrm{K}^{-1} \mathrm{~mol}^{-1}$. The experimental value of the residual entropy for a quenched sample coincides with this value within the estimated experimental error. Therefore, the order attained can only be at most $1 \%$ even for the most annealed sample in this work (Series 2). Thus we can only investigate the very initial part of the ordering process in $\mathrm{D}_{2} \mathrm{O}$ ice just as in $\mathrm{H}_{2} \mathrm{O}$ ice, because the relaxation time of the ordering process increases rapidly with decreasing temperatures, at which significant deuteron ordering might proceed.

\section{Activation enthalpy of the relaxation process}

A spontaneous temperature rise due to enthalpy release in the sample during the annealing experiment was followed intermittently. Three typical examples of the temperature drift are shown in Figure 3, where the straight lines refer to the temperature drift caused by heat leakage due to incompleteness of the adiabatic control. The asymptotic approach of the temperature to the straight line was analysed by an exponential decay function with a single characteristic time $\tau$, in the same manner as for $\mathrm{H}_{2} \mathrm{O}$ ice. The relaxation times determined in this way are summarized in Table II along with other data. From the Arrhenius plot of the relaxation time, the average activation enthalpy of the relaxation process was determined to be $(26 \pm 5) \mathrm{kJ} \mathrm{mol}^{-\mathrm{I}}$, which is very similar to the value, $(22 \pm 4) \mathrm{kJ} \mathrm{mol}^{-\mathrm{I}}$, for $\mathrm{H}_{2} \mathrm{O}$ ice in spite of large mass ratio of deuteron to proton. These values are within the range of $\mathrm{I}_{5}$ to 25 $\mathrm{kJ} \mathrm{mol}^{-1}$ reported by Sakabe and others (1970), Helmreich (1969), and Bishop and Glen ( 1969 ) for the activation enthalpy of the anomaly in pure and doped $\mathrm{H}_{2} \mathrm{O}$ ice at around Ioo K. These values for the activation enthalpy are very similar to those ascribed to the mobility of the Bjerrum defect, e.g. Jaccard (1959), and Engelhardt and Riehl (1966) gave 22 and $17 \mathrm{~kJ} \mathrm{~mol}^{-1}$ for this defect, respectively. This seems to suggest, as has been pointed out by Helmreich (1969) and Bishop and Glen (1969), that the Bjerrum fault participates in the ordering process of the deuteron configuration. 


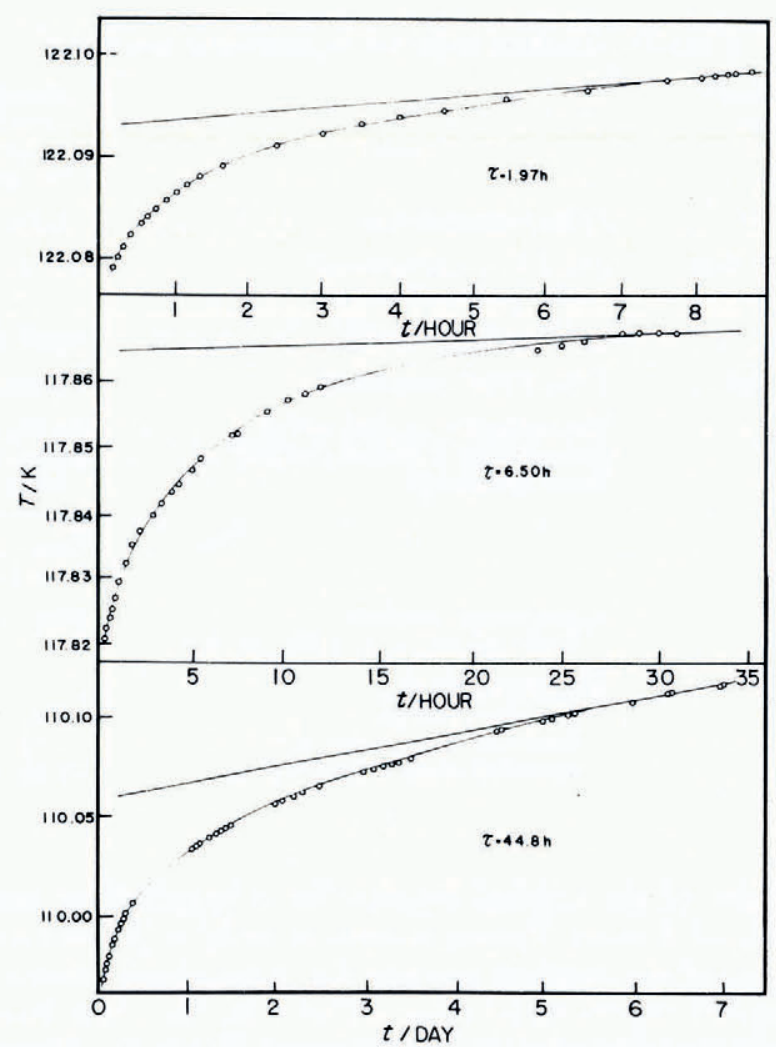

Fig. 3. Three typical examples of spontaneous temperature rise due to enthalpy relaxation of $\mathrm{D}_{2} \mathrm{O}$ ice.

TABle III. Data on ANNEALING EXPERIMENTS

$\begin{array}{ccc}\begin{array}{c}\text { Annealing } \\ \text { temperature }\end{array} & \begin{array}{c}\text { Annealing } \\ \text { time }\end{array} & \begin{array}{c}\text { Relaxation } \\ \text { time }\end{array} \\ T_{\text {an }} & t_{\text {an }} & \tau \\ \mathrm{K} & \mathrm{h} & \mathrm{h} \\ \mathrm{1} 10.04 & 166 & 44.8 \\ 112.89 & 92 & 12.2 \\ 113.46 & 68 & 17.2 \\ 117.85 & 3 \mathrm{I} & 6.50 \\ 120.85 & 28 & 4.63 \\ 122.09 & 9 & 1.97\end{array}$

\section{Discussion}

If we plot the heat capacity data reported by Long and Kemp (1936) in the form of $\left(C_{p} / T\right)$ versus $T$, we can find clearly an anomalous increase in heat capacity at around $120 \mathrm{~K}$. However, they did not mention this anomalous behaviour. Their failure to observe the anomalous temperature drift seems to be due to a difference in calorimetric principles. Since their calorimeter is of the isoperibol type, a correction for heat exchange between calorimeter cell and "quasi-isothermal" shield must be applied. After this correction, their calorimeter is reported to be capable of detecting a heat evolution (or absorption) exceeding an amount of $8 \times 10^{-4} \mathrm{cal} \mathrm{mol}^{-1} \mathrm{~min}^{-1}\left(1.9 \times 10^{-4} \mathrm{~J} \mathrm{~mol}^{-1} \mathrm{~min}^{-1}\right)$. The corresponding temperature drift rate is approximately $4 \mathrm{mK} / 20 \mathrm{~min}$. Therefore, if they had annealed the crystal for a long time, they might have observed the corresponding endothermic temperature drift. 
The present calorimetric observation is of course a kinetic effect, but reflects an underlying equilibrium property of the crystal. Unless the kinetic effect were associated with equilibrium "excess" heat capacity or enthalpy, we can not observe any spontaneous temperature variation under adiabatic conditions.

Chamberlain and Fletcher (I97I) and Johari and Jones (1975) have reported that the current peak due to thermally stimulated depolarization (TSD) observed at I Io $\mathrm{K}$ and $124 \mathrm{~K}$ in $\mathrm{H}_{2} \mathrm{O}$ and $\mathrm{D}_{2} \mathrm{O}$ ices is due to relaxation of frozen-in orientation polarization of water molecules in both crystals. The relaxation times for reorientation as determined by the TSD current and by the step-response method studied by Johari and Jones (1975) are plotted logarithmically against reciprocal temperature in Figure 4, along with the characteristic times determined by an enthalpy-relaxation experiment. The three sets of relaxation times for $\mathrm{H}_{2} \mathrm{O}$ ice can be connected by a single smoothed curve. The calorimetric data for $\mathrm{D}_{2} \mathrm{O}$ ice are higher by about one order of magnitude than the dielectric data and the difference is likely to be due to the different amounts of physical and chemical defects involved in the respective specimens. The deuteration level of the calorimetric specimen is $99.75 \%$, while that of the dielectric specimen is reported to be $98.75 \%$. In spite of some differences in their behaviour, however, this figure indicates essentially two facts. First, the degrees of freedom associated with the enthalpy relaxation are the same as in the dielectric relaxation. This explanation was also proposed by Stout and Giauque (1936) and by Johari (1976), but this figure provides convincing evidence for that. Secondly, some configurations of water molecule realized by that degree of freedom must differ energetically from others. This is the necessary condition for the relaxation to be observable calorimetrically.

Campbell and others ( 1967$)$ have calculated the lattice energies of an ice crystal in terms of multipole interaction as a function of orientation of the water molecules and found significant differences between the energy of the various configurations which must affect the thermodynamic properties of the crystal at temperatures around roo K. All of these facts lead to a picture concerning the ordering process of protons (or deuterons) in ice crystals. The water molecules are in an orientationally disordered state at high temperatures; all the

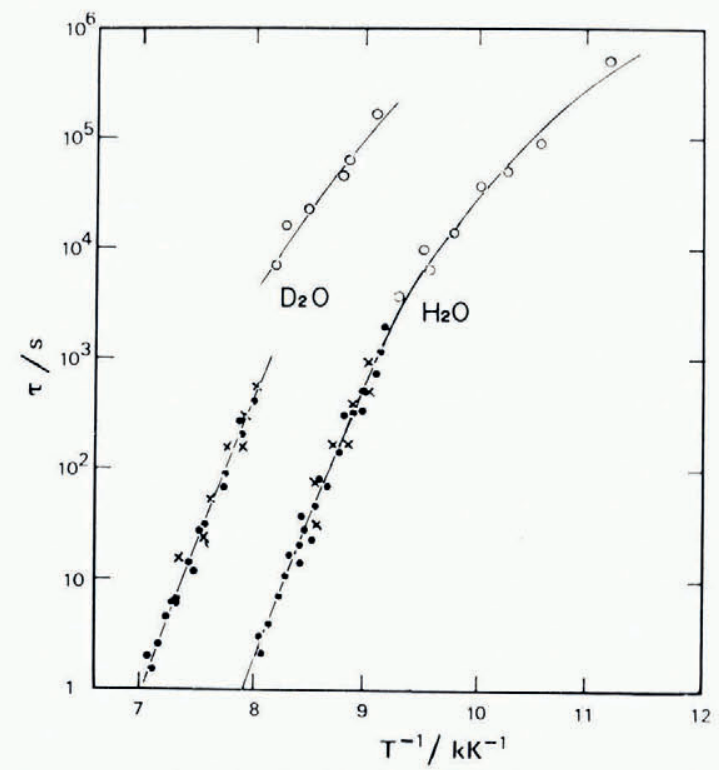

Fig. 4. Relaxation-time data of ice crystals determined by dielectric and calorimetric methods. $\bigcirc$ calorimetric method $\times$ TSD method, step-response (or bridge) method. 
six orientations of a water molecule might be realized essentially equally, as the Pauling (1935) model and the subsequent statistical model by Lieb (1967) assume ordinarily. As the crystal is cooled down, some of the proton configurations are favoured by intermolecular interactions among the water molecules, thus realizing a locally ordered state. The corresponding configurational heat capacity increases gradually as the temperature is lowered.

The configurational heat capacity would increase further and reach a maximum value at a transition point where an ordered state might be realized, if we could cool the crystal at an infinitely slow rate. The prolonged relaxation time, however, hinders the crystal from reaching the equilibrium state in an actual fast-cooling experiment and the proton configurational disorder is frozen at a certain temperature. The corresponding decrease in the configurational heat capacity occurs at $100-\mathrm{I}_{1} \mathrm{~K}$ for $\mathrm{H}_{2} \mathrm{O}$ ice and at $\mathrm{I}_{2} \mathrm{O}-\mathrm{I} 30 \mathrm{~K}$ for $\mathrm{D}_{2} \mathrm{O}$ ice, respectively. Consideration of the values of residual entropies for the quenched and the annealed samples of $\mathrm{H}_{2} \mathrm{O}$ and $\mathrm{D}_{2} \mathrm{O}$ ice crystals shows that we are concerned with very initial stage of the ordering process and the hypothetical transition point seems to be located much lower than roo K. Pitzer and Polissar (1956) predicted the existence of an order-disorder transition in $\mathrm{H}_{2} \mathrm{O}$ ice at about $60 \mathrm{~K}$ with a polar structure of the resulting phase.

In passing, we may mention the deviation of the calorimetric relaxation time of ice crystals from the high-temperature behaviour of the dielectric relaxation time,

$$
\tau=\tau_{0} \exp \left[B /\left(T-T_{0}\right)\right],
$$

where $\tau_{0}, B$, and $T_{0}$ are empirical constants. This equation was observed by Johari and Jones (1976) to hold for the dielectric relaxation time of $\mathrm{D}_{2} \mathrm{O}$ ice in the temperature range 1 $20<T / \mathrm{K}<170$, with the values $\tau_{0}=3 \times 10^{-16} \mathrm{~s}, B=828 \mathrm{~K}$ and $T_{0}=60 \mathrm{~K}$. Adachi and others (1968) observed a similar deviation of calorimetric relaxation time in the orientationally disordered crystal cyclohexanol below its "glass-transition" temperature and explained this from the viewpoint of plural relaxation mechanisms with different time constants. The multiplicity of dielectric relaxation times of $\mathrm{D}_{2} \mathrm{O}$ ice at low temperature was pointed out by Johari and Jones (1976). Probably, the calorimetric observation corresponds to the average relaxation time at a relatively high temperature but will correspond to the fastest process when the distribution of the relaxation times becomes wider as the temperature is lowered.

The excess enthalpy released during an annealing experiment in a frozen state is regained as an increased heat capacity when the crystal is heated. If we compare curves of $C_{p} / T$ versus $T$ for $\mathrm{H}_{2} \mathrm{O}$ and $\mathrm{D}_{2} \mathrm{O}$ ice crystals, we notice that the excess heat capacity of $\mathrm{D}_{2} \mathrm{O}$ ice appears about $20 \mathrm{~K}$ higher than that of $\mathrm{H}_{2} \mathrm{O}$ ice. This temperature difference is likely to reflect the difference in equilibrium properties of both crystals. A Curie-Weiss representation of the dielectric constants of both crystals by Johari and Jones (1976) indicated that the extrapolated Curie point was $27 \mathrm{~K}$ higher for $\mathrm{D}_{2} \mathrm{O}$ than that for $\mathrm{H}_{2} \mathrm{O}$ ice. Therefore, the higher peak temperature of excess heat capacity for $\mathrm{D}_{2} \mathrm{O}$ ice seems to reflect the correspondingly higher Curie temperature. An increase in the Curie point of a hydrogen-bonded crystal on deuteration is exemplified by many systems. Chan (1973) gave a possible interpretation of the increase in the Curie temperature from the viewpoint of isotopic effect on lattice vibrational frequencies and zero-point energy.

Nevertheless, the relaxation times of both crystals reach a calorimetric time scale $\left(\approx \mathrm{IO}^{4} \mathrm{~s}\right)$ at $104 \mathrm{~K}$ and $12 \mathrm{I} \mathrm{K}$, respectively, and therefore we can observe only a high temperature part (very initial part) of the ordering process for both crystals. The amount of excess heat capacity is nearly the same for both crystals when comparing the same time-scale experiments, in spite of the difference in their respective Curie temperatures. This fact seems to indicate that the relaxation time for the reorientational degree of freedom is governed by a static property. The important role configurational entropy plays in the relaxational properties of frozen system was first proposed by Adam and Gibbs (1965). If this mechanism is operative in the 
case of ice crystals, we must abandon the assumption of single relaxation time employed in the analysis of temperature-time curves from the calorimeter. Configurational order and hence the relaxation time must change as the time elapses in one experiment. The experimental verification of this mechanism requires a much better performance of the adiabatic control because of the smallness of the excess enthalpy involved and because of the ambiguity in determining the "base line" due to heat leakage. In this respect, it may be interesting to study a solid-solution system, $\mathrm{H}_{2} \mathrm{O}-\mathrm{D}_{2} \mathrm{O}$. The Curie point of the system may be situated between those of the parent crystals. The complexity of the system is increased by the isotopic substitution, which is expected to shorten the relaxation time of the system. Alternatively the impurity effect might cause a shortening of the relaxation time. Thus, we can hope to observe an enhanced heat-capacity anomaly.

In any event, we could detect the relaxational heat-capacity anomaly in $\mathrm{D}_{2} \mathrm{O}$ ice in an analogous way to that in $\mathrm{H}_{2} \mathrm{O}$ ice. This means that the rate of rearrangement of protons (deuterons) is on the calorimetric time-scale $\left(\mathrm{IO}^{3}-\mathrm{IO}^{6} \mathrm{~s}\right)$ at a temperature range where energy differences among the possible orientations of the disordered water molecules promote ordering even slightly. The recent observation of a heat-capacity anomaly in another orientationally disordered crystal, CO, around $18 \mathrm{~K}$ by Atake and others (1976) was interpreted along the same lines. The relaxational nature of the anomalies in CO and ice crystals is seemingly not independent of the existence of residual entropy in both crystals.

Up to this point, we have assumed implicitly that the observed heat-capacity anomaly was an intrinsic property of the ice crystal that was brought about by the reorienting motion of defects which lost their mobility as the temperature was lowered. There might be another possibility, that the anomaly is associated with some local order induced by lattice defects. However, we can scarcely expect to detect calorimetrically the thermal anomaly due to such defects existing in minor concentration. The amount of orientational defects in pure ice is considered to be of the order of $10^{-7} \mathrm{~mol} \%$ even at $-10^{\circ} \mathrm{C}$, and that of ionic defects is much less. An experiment to see how the entropy of an ice crystal can be removed by doping with a particular impurity might be helpful to clarify the nature of the relaxational anomaly. If the corresponding defect were to induce some short-range local order in water molecules in the neighbourhood of the defect, we would expect an increased amount of excess heat capacity in a doping experiment, because the increase in defect concentration will increase the number of regions in which some local order is induced. The excess heat capacity will be observed at essentially the same temperature as in a pure crystal. If the defect were to shorten the reorganization rate of the whole system, we could expect an increased heat-capacity anomaly that starts from a lower temperature. Thus the doping experiment will throw some light on the "intensive" and the "extensive" roles of the lattice defects.

\section{MS. received 24 August 1977 and in revised form 26 April 1978}

\section{REFERENGES}

Adachi, K., and others. 1968. Phase changes in crystalline and glassy-crystalline cyclohexanol, [by] K. Adachi, H. Suga and S. Seki. Bulletin of the Chemical Society of Japan, Vol. 41, No. 5, p. 1073-87.

Adam, G., and Gibbs, J. H. 1965 . On the temperature dependence of cooperative relaxation properties in glass-forming liquids. Fournal of Chemical Physics, Vol. 43, No. 1, p. 139-46.

Atake, T., and others. 1976 . Anomaly in the heat capacity of crystalline carbon monoxide at $18 \mathrm{~K}$ associated with orientational ordering, [by] T. Atake, H. Suga and H. Chihara. Chemistry Letters, 1976, No. 6, p. 567-71.

Besley, L., and Bottomley, G. A. I 973 . Vapour pressure of normal and heavy water from 273.15 to $298.15 \mathrm{~K}$. Journal of Chemical Thermodynamics, Vol. 5, No. 3, p. 397-410.

Bishop, P. G., and Glen, J. W. 1969. Electrical polarization effects in pure and doped ice at low temperatures. (In Riehl, N., and others, ed. Physics of ice: proceedings of the international symposium on physics of ice, Munich, Germany, September 9-14, rg68. Edited by N. Riehl, B. Bullemer, H. Engelhardt. New York, Plenum Press, p. 492-501.) 
Campbell, E. S., and others. 1967. Interpretation of the energy of hydrogen bonding; permanent multipole contribution to the energy of ice as a function of the arrangement of hydrogens, [by] E. S. Campbell, G. Gelernter, H. Heinen and V. R. G. Moorti. Journal of Chemical Physics, Vol. 46, No. 7, p. 2690-707.

Chamberlain, J. S., and Fletcher, N. H. 1971. Low temperature polarization effects in ice. Physik der kondensierten Materie, Bd. 12, Ht. 3, p. 193-209.

Chan, R. K. 1973. Discussion. (In Whalley, E., and others, ed. Physics and chemistry of ice: papers presented at the Symposium on the Physics and Chemistry of Ice, held in Ottawa, Canada, 14-18 August 1972. Edited by E. Whalley, S. F. Fones, L. W. Gold. Ottawa, Royal Society of Canada, p. 306.)

Engelhardt, H., and Riehl, N. 1966. Zur protonischen Leitfähigkeit von Eis-Einkristallen bei tiefen Temperaturen und hohen Feldstärken. Physik der kondensierten Materie, Bd. 5, Ht. 2, p. 73-82.

Giauque, W. F., and Stout, J. W. I 936 . The entropy of water and the third law of thermodynamics. The heat capacity of ice from 15 to $273^{\circ} \mathrm{K}$. Fournal of the American Chemical Society, Vol. 58, No. 7, p. 1 I44-50.

Haida, O., and others. I973. Enthalpy relaxation at glass transition temperature of heavy ice crystal, by $O$. Haida, H. Suga and S. Seki. Proceedings of the Japan Academy, Vol. 49, No. 3, p. 191-95.

Haida, O., and others. 1974 . Calorimetric study of the glassy state. X. Enthalpy relaxation at the glass-transition temperature of hexagonal ice, [by] O. Haida, T. Matsuo, H. Suga and S. Seki. Journal of Chemical Thermodynamics, Vol. 6, No. 9, p. 815-25.

Helmreich, D. I 969 . Elastic anomalies of ice at low temperatures. (In Riehl, N., and others, ed. Physics of ice: proceedings of the international symposium on physics of ice, Munich, Germany, September 9-14, 1968. Edited by $\mathcal{N}$. Riehl, B. Bullemer, $H$. Engelhardt. New York, Plenum Press, p. 231-38.)

Helmreich, D. 1973. Imperfection-induced phase transformation in $\mathrm{D}_{2} \mathrm{O}$ ice Ih. (In Whalley, E., and others, ed. Physics and chemistry of ice: papers presented at the Symposium on the Physics and Chemistry of Ice, held in Ottawa, Canada, I4-18 August 1972. Edited by E. Whalley, S. F. Jones, L. W. Gold. Ottawa, Royal Society of Canada, p. 291-94.)

Jaccard, C. 1959. Étude théorique et expérimentale des propriétés électriques de la glace. Helvetica Physica Acta, Vol. 32, Fasc. 2, p. 89-128.

Johari, G. P. 1976. Glass transition and secondary relaxations in molecular liquids and crystals. Annals of the New York Academy of Sciences, Vol. 279, No. 10, p. I 1 7-40.

Johari, G. P., and Jones, S. J. 1975. Study of the low-temperature "transition" in ice Ih by thermally stimulated depolarization measurements. Fournal of Chemical Physics, Vol. 62, No. 10, p. 4213-23.

Johari, G. P., and Jones, S. J. 1976. Dielectric properties of polycrystalline $\mathrm{D}_{2} \mathrm{O}$ ice Ih(hexagonal). Proceedings of the Royal Society of London, Ser. A, Vol. 349 , No. 1659, p. 467-95.

Lieb, E. H. 1967. Residual entropy of square ice. Physical Review, Vol. 162, No. 1, p. 162-72.

Long, E. A., and Kemp, J. D. 1936 . The entropy of deuterium oxide and the third law of thermodynamics. Heat capacity of deuterium oxide from 15 to $298^{\circ} \mathrm{K}$. The melting point and heat of fusion. Fournal of the American Chemical Society, Vol. 58, No. 10, p. 1829-34.

Nagle, J. F. I 666 . Lattice statistics of hydrogen bonded crystals. I. The residual entropy of ice. Fournal of Mathematical Physics, Vol. 7, No. 8, p. $1484-91$.

Pauling, L. 1935. The structure and entropy of ice and of other crystals with some randomness of atomic arrangement. Fournal of the American Chemical Society, Vol. 57, No. 12, p. 2680-84.

Pitzer, K. S., and Polissar, J. 1956. The order-disorder problem for ice. Fournal of Physical Chemistry, Vol. 6o, No. 8, p. $1140-42$.

Rossini, F. D., and others. 1940. Heat and free energy of formation of deuterium oxide, by F. D. Rossini, J. W. Knowlton and H. L. Johnston. Journal of Research of the National Bureau of Standards, Vol. 24, No. 4, p. 369-88.

Sakabe, Y., and others. I970. Dielectric dispersion of NaOH-doped ice at low temperatures, [by] Y. Sakabe, M. Ida and S. Kawada. Journal of the Physical Society of Japan, Vol. 28, No. 1, p. 265. 